\title{
Gabriella Radica, L'histoire de la raison. Anthropologie, morale et politique chez Rousseau
}

\section{Paola Sosso}

\section{(2) OpenEdition}

1 Journals

\section{Edizione digitale}

URL: http://journals.openedition.org/studifrancesi/7582

DOI: $10.4000 /$ studifrancesi.7582

ISSN: 2421-5856

\section{Editore}

Rosenberg \& Sellier

\section{Edizione cartacea}

Data di pubblicazione: 1 décembre 2009

Paginazione: 629

ISSN: 0039-2944

\section{Notizia bibliografica digitale}

Paola Sosso, «Gabriella Radica, L'histoire de la raison. Anthropologie, morale et politique chez Rousseau»,

Studi Francesi [Online], 159 (LIII | III) | 2009, online dal 30 novembre 2015, consultato il 09 janvier 2021 URL: http://journals.openedition.org/studifrancesi/7582 ; DOI: https://doi.org/10.4000/studifrancesi. 7582

Questo documento è stato generato automaticamente il 9 janvier 2021.

\section{(c) (1)}

Studi Francesi è distribuita con Licenza Creative Commons Attribuzione - Non commerciale - Non opere derivate 4.0 Internazionale. 


\title{
Gabriella Radica, L'histoire de la raison. Anthropologie, morale et politique chez Rousseau
}

\author{
Paola Sosso
}

\section{NOTIZIA}

GABRIELLA RADICA, L'histoire de la raison. Anthropologie, morale et politique chez Rousseau, Paris, Champion, 2008 («Les dix-huitièmes siècles», 119), pp. 805.

1 «La règle juste» è il titolo della prima sezione di questo volume che, ricollegandosi in modo puntuale ai grandi studiosi del pensiero del Ginevrino, definisce in quale modo Rousseau si sia distanziato dal giusnaturalismo: la rottura appare radicale nella divergenza di metodo, nella diversa definizione della ragione e in una differente concezione antropologica. Considerata l'incapacità del diritto naturale di regolare $\mathrm{i}$ conflitti, diviene per Rousseau necessario lo stato civile e quindi la volontà generale. L'artificio volontario e razionale si inserisce allora nei rapporti umani, insieme a una «objectivité indéniable» (p. 167) che impedisce la creazione di leggi arbitrarie e ingiuste. Nel secondo volet, "La sphère individuelle», sempre costruito su un dialogo continuo con i grandi critici che l'hanno preceduta, l'autrice crea una serie di rapporti interessanti tra la concezione di Rousseau e gli scritti di Pascal, La Rochefoucauld e Fénelon. La studiosa ritorna anche sul dibattito relativo al razionalismo, mettendo in luce le diverse sfumature che questa facoltà assume nell'opera di Rousseau, secondo il quale la comprensione di questa acquisizione umana va inserita nella complessità della storia dell'uomo. Lo studio della bontà, della virtù e della ragione porta all'analisi dell'Émile, il cui primo obiettivo è quello di «apprendre à vivre». A tal fine la ragione condurrà verso ciò che è utile: la riduzione del desiderio e il controllo delle proprie debolezze. Dall'utile si giunge, nell'ottica di Rousseau, all'aspetto morale, argomento della terza parte, «Le monde moral». Lo studio della Nouvelle Héloïse, variazione romanzesca dell'antropologia rousseauiana, mostra come virtù, morale, retorica $\mathrm{e}$ 
ragione siano riproposti dal Ginevrino attraverso una finzione dove ancora una volta si conferma che norme e credenze derivano innanzitutto dalle facoltà più libere e creative dell'uomo. 